\title{
Taxonomic overview of Polymixis serpentina (Treitschke, I825) species-group, with the description of a new species (Lepidoptera, Noctuidae, Xyleninae)
}

\author{
Oleg Pekarsky ${ }^{1, \dagger}$
}

\author{
I H-1068 Budapest, Felsöerdösor u. 16-18, Hungary \\ † urn:lsid:zoobank.org:author:40DC027F-FCF3-4953-AC60-C071E814A768 \\ Corresponding author: Oleg Pekarsky (opbp@t-online.hu)
}

Academic editor: D. Lafontaine | Received 29 February 2012 | Accepted 28 May 2012 | Published 14 June 2012

urn:lsid:zoobank.org:pub:12485229-D230-4DB9-9COD-C38839B97FAC

Citation: Pekarsky O (2012) Taxonomic overview of Polymixis serpentina (Treitschke, 1825) species-group, with the description of a new species (Lepidoptera, Noctuidae, Xyleninae). ZooKeys 201: 15-26. doi: 10.3897/zookeys.201.3035

\begin{abstract}
The taxa of the Polymixis serpentina (Treitschke, 1825) species-group are revised. The external and genital features of all known taxa and a new species, P. ivanchiki sp. n. (Lebanon, Israel, Turkey and Iran) are described and illustrated. P. serpentina iatnana Hacker, 1996, is treated here as a species distinct from P. serpentina (stat. n.). A diagnostic comparison of the members of the species-group is provided; descriptions of the genitalia of Polymixis serpentina minoica Fibiger, 1992 and P. iatnana are given for the first time.
\end{abstract}

\section{Keywords}

Lepidoptera, Noctuidae, Polymixis serpentina species-group, new species, Lebanon

\section{Introduction}

Polymixis Hübner, [1820] is a Palearctic genus of the subfamily Xyleninae. During the last thirty years several remarkable works have been published dealing with the taxonomic aspects of the genus (Beck 1996, 1999; Ronkay et al. 2001). In the latest revisionary work (Witt and Ronkay 2011) P. serpentina is attributed to the subgenus Polymixis Hübner, [1820]. Actually, two insular subspecies are distinguished: P. serpentina minoica from Crete and P. serpentina iatnana from Cyprus; both were described 
based on external features only. The authors (Fibiger 1992; Hacker 1996) stated in the descriptions that the genitalia show no difference between the subspecies. The existing differences in genitalia structures of the three subspecies of P. serpentina are described and discussed in detail in the present paper.

\section{Systematic part}

\section{Polymixis ivanchiki sp. n.}

urn:lsid:zoobank.org:act:37121E63-1CB5-49F7-97BF-1B256CD340DB

http://species-id.net/wiki/Polymixis_ivanchiki

Figs $1-2$

Holotype. Male, Lebanon N., Fnaideg env., h-1440m, 12.x.2007, leg. Krueger, Saldaitis; slide No.: OP0941m (coll. O. Pekarsky, deposited in the HNHM Budapest).

Paratypes. Lebanon. $4 \hat{\delta} \widehat{\partial}, 1$ q Caza Dchare, Berhalioun, h-700m, 22.x.2008, leg. Punta, slide No: OP1352m (male) (coll. O. Pekarsky); 20 ふึग, 6 우우 from the

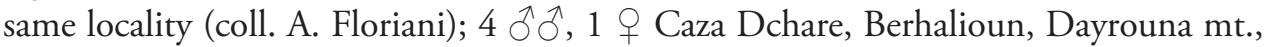
h-1200 m, 24-25.x.2008, leg. E. Punta, (coll. A. Floriani); 1 + Caza Aaakkar, Bezbina, h-700m, 26.x.2008, leg. Punta, (coll. O. Pekarsky); 1 ○ from the same locality, (coll. A. Floriani); 2 우 Cedrus Mts., Aayoun Urghouch, h-2130m, 10.x.2007, leg. Krueger, Saldaitis; 1 o Laqlouq env., h-1600m, 14.x.2007, leg. Krueger, Saldaitis, slide No: OP0942f (female) (coll. O. Pekarsky); 1 q 60 km S v. Beirut, 30.X.1963, leg. E. \& A. Vartian, slide No: OP1347f (female) (coll. NHMW). Turkey. 1 đ, 2 우 9 Turkey, Prov. Hatay, 6 km N of Yayladagi, 1100 m, 3600 E, 3605 N, 20.x.1993, leg. Gy. Fábián, B. Herczig, Gy. László, K. Szeőke, slide No: OP1029f (female) (coll. G. Ronkay); 1 o, Prov. Urfa, Halfeti, valley of Euphrat, 500 m, 37² $52^{\prime} \mathrm{E}, 37^{\circ} 14^{\prime} \mathrm{N}, 19 . x .1993$, leg. Gy. Fábián, B. Herczig, Gy. László, K. Szeőke, slide No: OP1428m (male) (coll. G. Ronkay). Israel. 1 ภ, N. Galilea, Nimrod, 800 m., 10-20.10.2004, ligh trap (coll. P. Gyulai), 2 ठิ $\widehat{x}$, Jerusalem, X.2006, leg. V. Kravchenko, slide No: OP1632m (male)

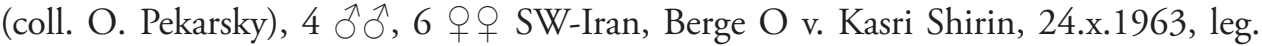
Kasy \& Vartian, slide Nos: OP1348m (male), OP1349f (female) (coll. NHM Vienna).

Diagnosis. Polymixis ivanchiki is a sister taxon of P. serpentina and is hardly distinguished externally from it, although the genitalia show clearly recognisable differences in both sexes. The forewing pattern of the two species is very similar, only the shape of reniform stigma show certain specific features. The reniform stigma of $P$. ivanchiki is slenderer, more S-shaped with a finely lunulate inner dark line, whereas that of $P$. serpentina serpentina is larger and more or less elliptical, with more parallel sides. The male genitalia of the two species are similar in most characters. The most significant difference between the two species is the shape of juxta. Polymixis ivanchiki has a characteristic anchor-like juxta, wide medially, and tapered evenly posteriorly into a long acutely angled process with a posteriorly tapering lateral process on each side with serrated inner edges at their tips; the juxta of 

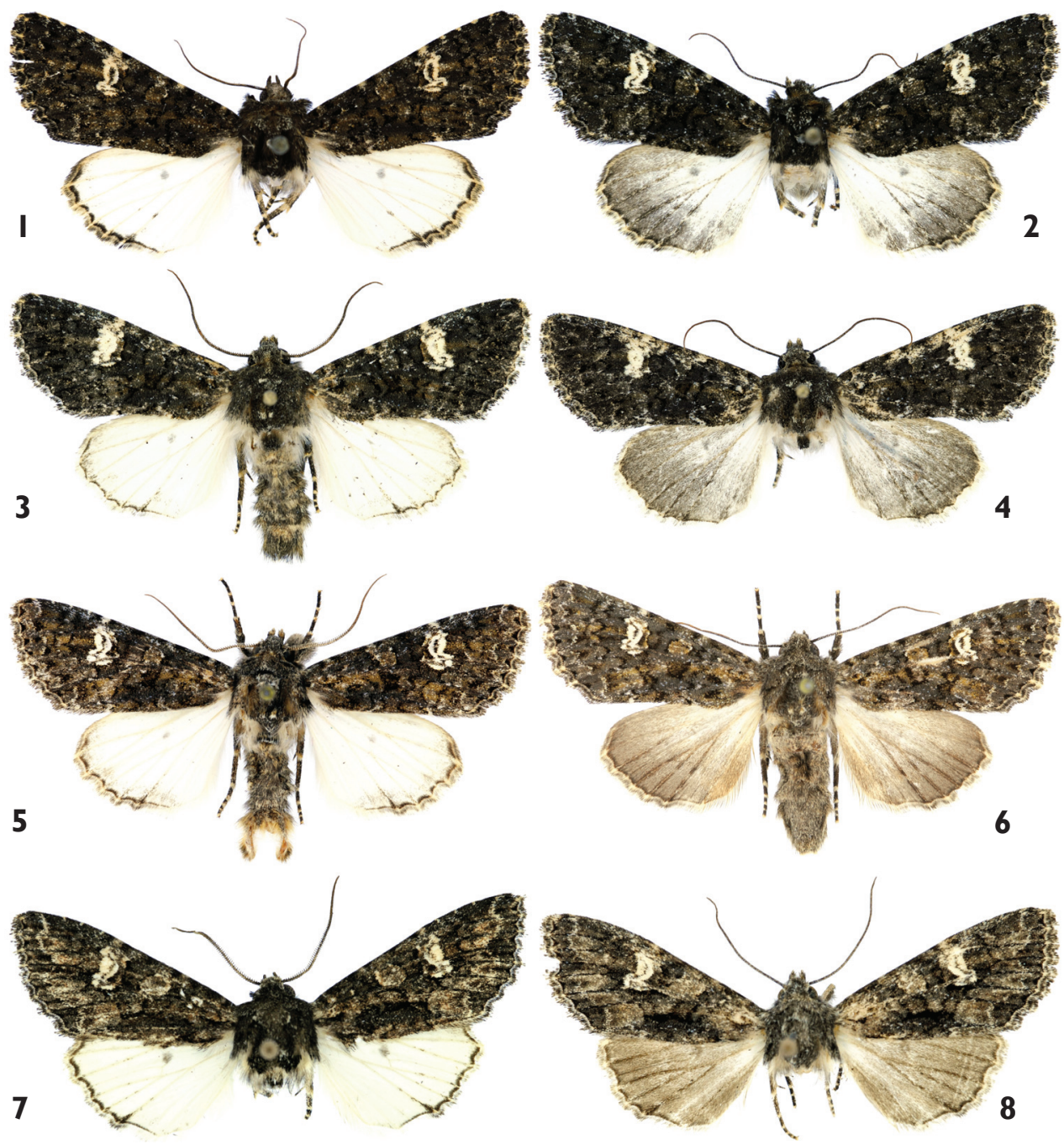

Figures I-8. Adults. I, 2 Polymixis ivanchiki sp. n. I holotype male, Lebanon $\mathbf{2}$ paratype female, Lebanon 3, 4 P. serpentina serpentina $\mathbf{3}$ male, Slovenia 4 female, Slovenia 5, 6 P. serpentina minoica 5 male, Greece, Crete $\mathbf{6}$ female, Greece, Crete 7, 8 P. iatnana $\mathbf{7}$ paratype male, Cyprus $\mathbf{8}$ female, Cyprus.

P. serpentina has wide posterior extension, less broad medial part and the two lateral arms lack the apical serration.

The most conspicuous difference between the female genitalia of two species can be found in the shape of the antrum. The posterior (anal) margin of the antrum of $P$. ivanchiki has a very deep cleft, which reaches the middle of antrum, whereas P. serpentina has only a slight, shallow cleft.

Description. Male (Fig. 1). Wingspan 38-40 mm, length of forewing $19 \mathrm{~mm}$. Head, thorax and forewing dark brownish grey mixed with black hair-like scales. 
Forewing elongate, narrow; costa straight with white patches; outer margin with rather straight termen; most elements of forewing pattern rather blurred, except prominent white-defined reniform stigma; all but one crosslines black; basal line straight; subbasal line zigzagged; antemedial line waved; medial fascia a row of black streaks; postmedial line curved and dentate; subterminal line discontinuous, pale whitish, strongly sinuous, defined by short, black arrowhead spots at inner side; terminal line a row of tiny blackish triangles; orbicular stigma more or less rounded, formed by two black lateral arches filled with ground colour; reniform stigma large, white with narrow, black, lunulate inner line; fringes (cilia) as ground colour, finely chequered by whitish streaks at veins. Hindwing shining white with some black scales on veins, discal spot pale gray, terminal line black; cilia pale yellow mixed sparsely with black hair-like scales.

Female (Fig. 2). As male but with considerably darker suffused hindwing.

Male genitalia (Figs 9-12). Genital armature well-sclerotized; uncus weak, small and short, flattened and broad at base, tapering towards finely rounded and slightly hairy apex; tegumen broad, 0.67 times length of vinculum; penicular lobes small, rounded, bearing long setae; juxta anchor-like wide medially with two narrow and posteriorly tapered lateral arms with serrated inner edges towards apex; central posterior process long, thin, evenly tapering posteriorly; vinculum U-shaped. Valvae elongate with narrower distal half; cuculli asymmetrical, left one small and narrow, right one larger, apically more rounded, ventral surfaces densely setose on both cuculli; corona absent; sacculus large, elongate; clavus represented by a long, flat hump; clasper (harpe) straight, bar shaped; ampulla long, stick-like, with evenly tapered distal half and broad, reversed Y-shaped base. Aedeagus cylindrical, curved ventrally in distal part. Vesica tubular, everted forward then bent dorsad; basal tube short, subbasal bulb much wider, inflated, armed by narrow, elongated terminal field of spiniform cornuti; distal diverticulum small.

Female genitalia (Figs 25-27). Ovipositor medium-long, papillae anales elongated, hairy, with long setae on sides and shorter setae apically. Apophyses anteriores strong, with spatulate tips; apophyses posteriores thin and slightly longer than apophyses anteriores. Antrum (ostium bursae) large, broad, trapezoidal, strongly sclerotized, incised caudally forming deep cleft on ventral surface extending from posterior margin almost to middle of antrum. Ductus bursae flattened, semi-tubular, strongly sclerotized, medially folded and twisted. Appendix bursae conical, with sclerotized ribs and wrinkles; corpus bursae membranous, ovoid with four signumstripes of different lengths.

Etymology. The new species named in honour of Ukrainian zoologists, Ivanchik Taisiya Semenivna (1937-2007) and Ivanchik Grigoriy Semenovich (1929-2011), teachers of Department of Zoology, Faculty of Biology, Yuriy Fedkovych Chernivtsi National University.

Distribution. The species is distributed in the Near East (Israel, Lebanon, SW Iran) and the southern parts of Turkey (provinces Hatay and Urfa). 

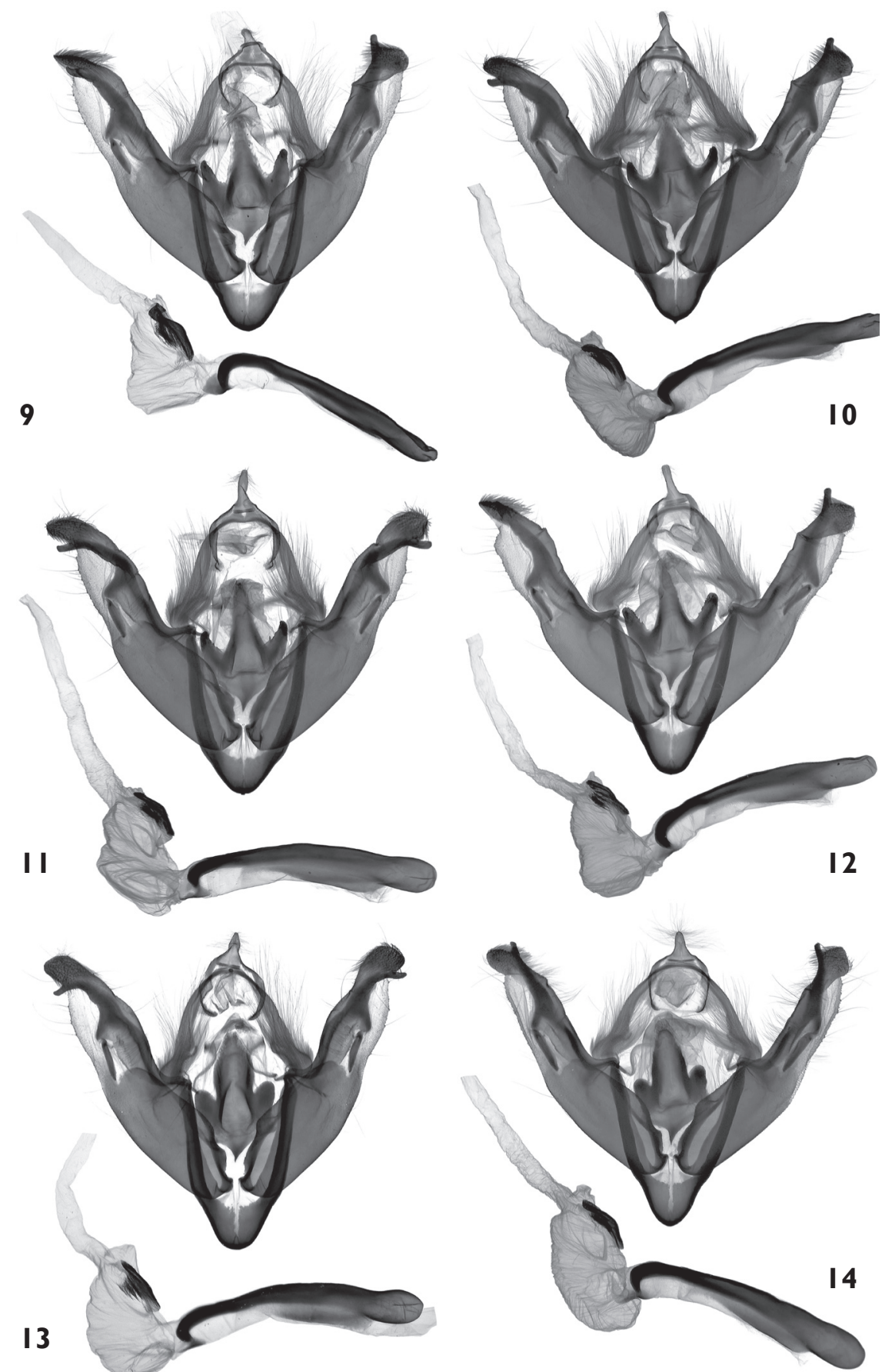

Figures 9-I4. Male genitalia. 9-I 2 Polymixis ivanchiki sp. n. 9 holotype, Lebanon, slide No. OP0941m 10 paratype, Lebanon, slide No. OP1352m I I paratype, SE Turkey, slide No. OP1428m I 2 paratype, SW Iran, slide No. OP1348m I3, I4 Polymixis serpentina serpentina I3 Slovenia, slide No. OP0939m I4 Croatia, slide No. OP1333m. 


\section{Polymixis serpentina serpentina (Treitschke, 1825)}

http://species-id.net/wiki/Polymixis_serpentina_serpentina

Figs 3, 4

Material examined. Slovenia, slide Nos: ô OP0939m, q OP0940f; Croatia, slide

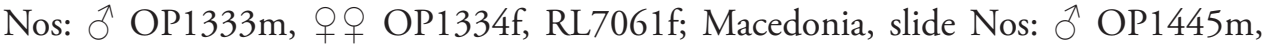

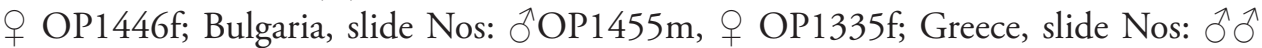
OP1014m, OP1336m, OP1338m, 우 OP1015f, OP1337f, OP1339f; Italy, Pu-

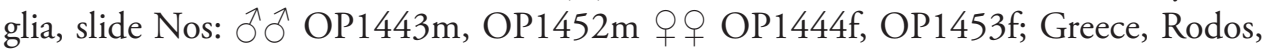

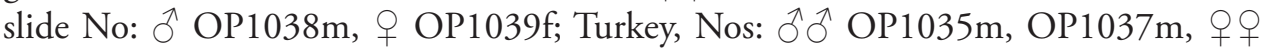
OP1028f, OP1036f.

Male genitalia (Figs 13-20). A detailed description of genitalia of this taxon is given by Ronkay et al. (2001). To this text it is possible to add only some more details of the characteristic structure of the juxta. In the typical populations of $P$. serpentina serpentina from Croatia the juxta has a wide posterior extension and medial part has a posterolaterally directed lobe or lateral arm on each side without any serration.

Female genitalia (Figs 28-36). Described by Ronkay et al. (2001). In addition that description, it is worth highlighting the importance of the shape of the posterior margin of the antrum, which has only a slight, rounded concavity in the middle. This shape of antrum is characteristic for the P. serpentina serpentina populations from Croatia (type locality) and adjacent areas (Slovenia, Bulgaria) (Figs 28-30). Females from the more eastern areas (north and central Greece, central and south Turkey) have the posterior margin of antrum more deeply incised (Figs 31-36). It should be noted that the genitalia figure in Noctuidae Europaeae 5 (Fig. 141) shows the male genitalia of P. serpentina minoica, whereas Fig. 335 illustrates the female genitalia of the nominate subspecies.

Note. Moths from Rhodes Island have some slight differences in male genital structure; further studies on a larger sample of material are needed to clarify the taxonomic situation of this insular population. It is not impossible that this population represents another, as yet undescribed, subspecies of $P$. serpentina.

\section{Polymixis serpentina minoica Fibiger, 1992}

http://species-id.net/wiki/Polymixis_serpentina_minoica Figs 5, 6

Material examined. Greece, Crete slide Nos: $\widehat{\partial}$ OP $1283 \mathrm{~m}, \mathrm{OP} 1345 \mathrm{~m}$, 우우 OP1284f, OP1340f, OP1346f.

Male genitalia (Figs 21, 22). The genitalia of this taxon were not described in the original description. It was stated that there were no differences between the two subspecies. There are, however, some recognisable differences between the structure of the genitalia of the Cretan and the other populations of P. serpentina. The ground plan of the male genitalia of $P$. serpentina minoica and the nominotypical subspecies 

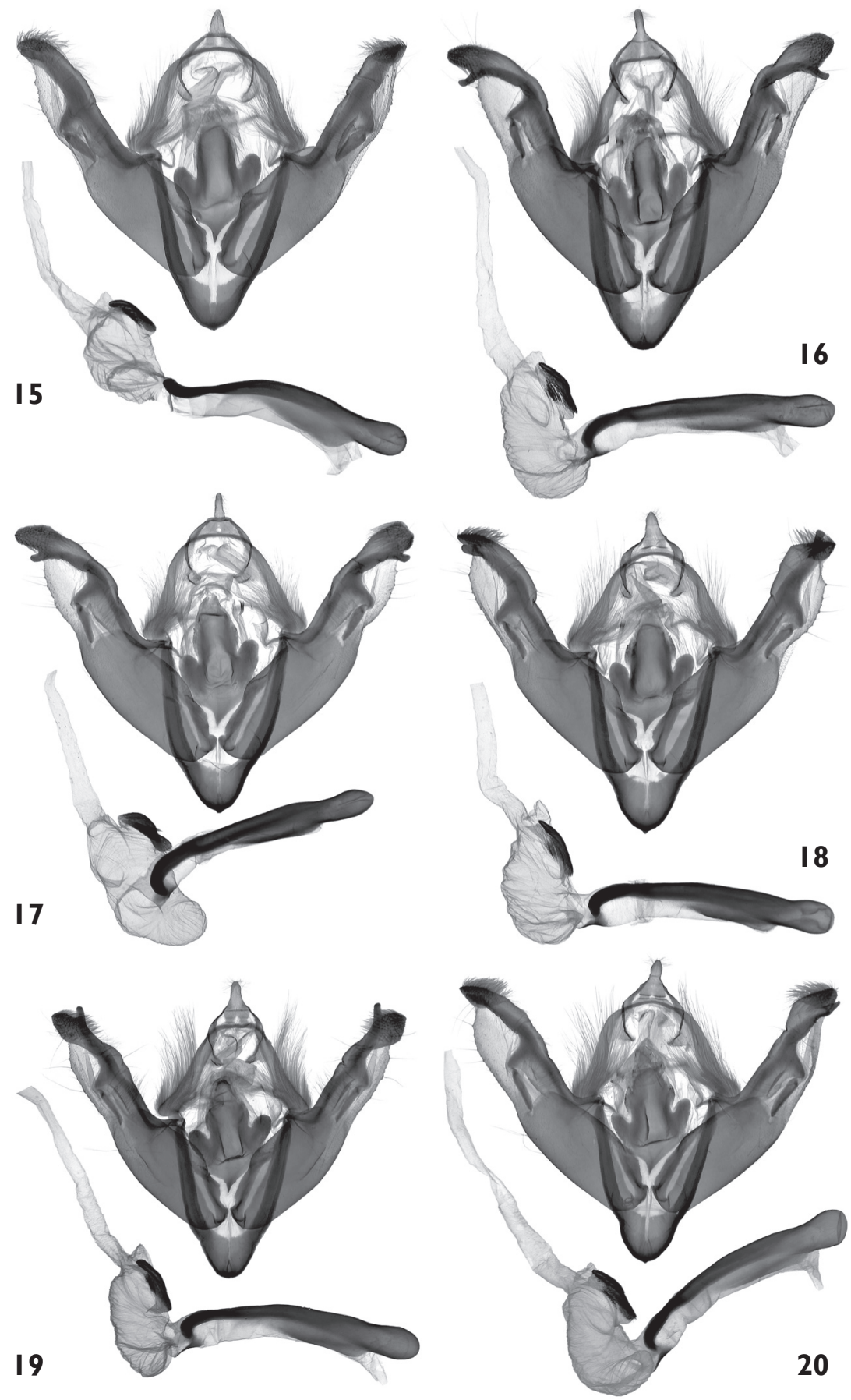

Figures 15-20. Male genitalia. I5-20 Polymixis serpentina serpentina 15 Central Greece, slide No. OP1014m 16 Greece, Rhodos, slide No. OP1038m 17 Turkey, Antalya prov., slide No. OP1035m 18 Turkey, Ankara prov., slide No. OP1037m 19 Italy, Puglia, slide No. OP1443m 20 Bulgaria, slide No. OP1455m. 

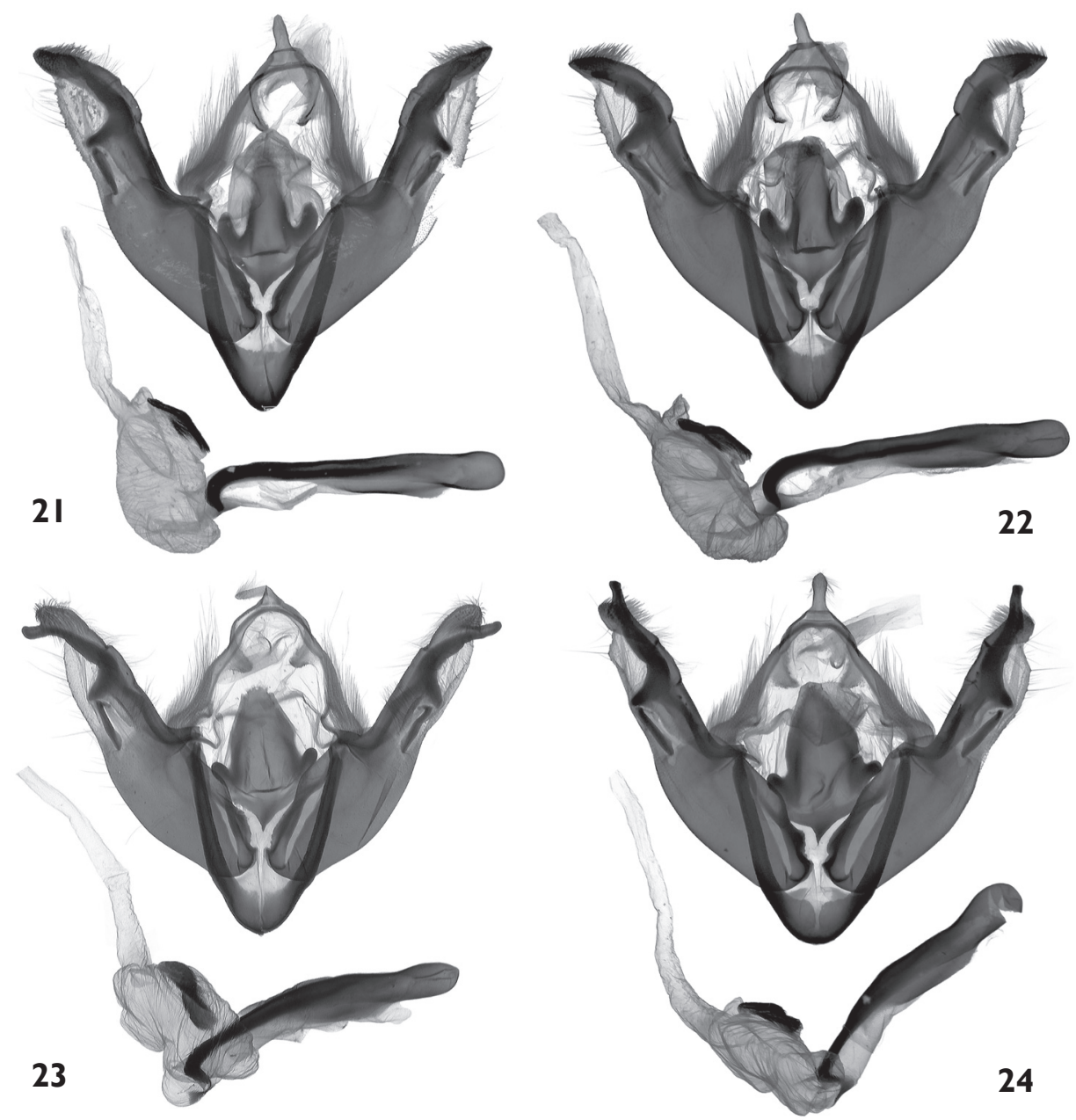

Figures 2 I-24. Male genitalia. 2I, 22 Polymixis serpentina minoica 2 I Greece, Crete, slide No. OP1283m 22 Greece, Crete, slide No. OP1345m 23,24 Polymixis iatnana 23 Cyprus, slide No. OP1030m 24 Cyprus, slide No. OP1282m.

is the same, but the shape of the juxta is different and all parts of the posterior half of valvae are more massive, being more intensively sclerotized. The posterior extension of juxta is similar to that of $P$. serpentina serpentina, but its lateral arms are more elongated, slightly curved, and significantly more divergent from the basal plate. The valvae are wider, and the costa, triangular basal plate, and its extension, appear rough and massive due to their stronger sclerotization; $P$. s. serpentina has narrower valvae with all parts of their distal sections being finer and thinner.

Female genitalia (Figs 37-39). The copulatory organ of ssp. minoica differ from those of the ssp. serpentina in the on average shallower concavity on the posterior margin of antrum. 

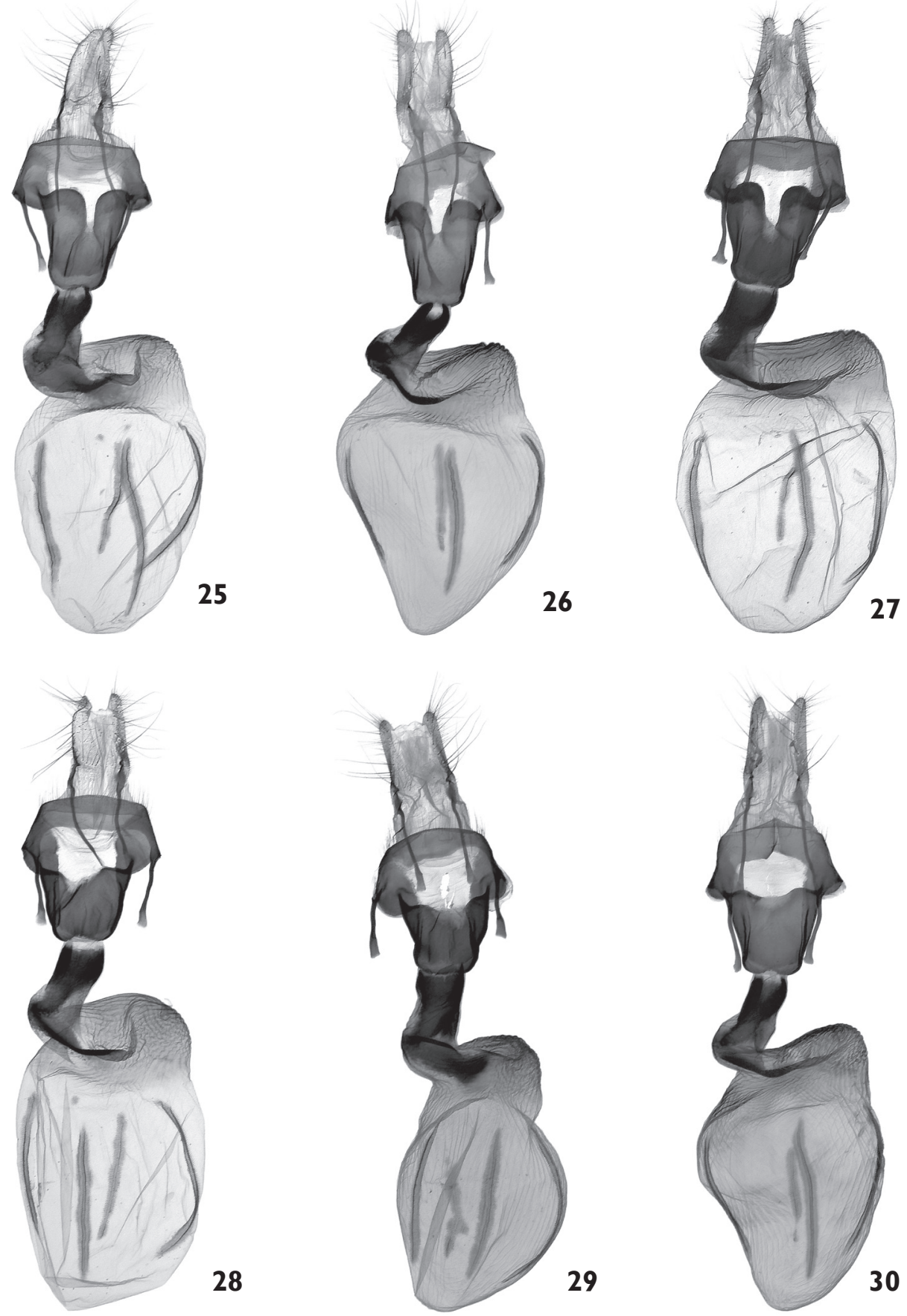

Figures 25-30. Female genitalia. 25-27 Polymixis ivanchiki sp. n. 25 paratype, Lebanon, slide No. OP0942f 26 paratype, Lebanon, slide No. OP1347f 27 paratype, SE Turkey, slide No. OP1029f 28-30 Polymixis serpentina serpentina 28 Slovenia, slide No. OP0940f 29 Croatia, slide No. OP1334f 30 Bulgaria, slide No. OP1335f. 

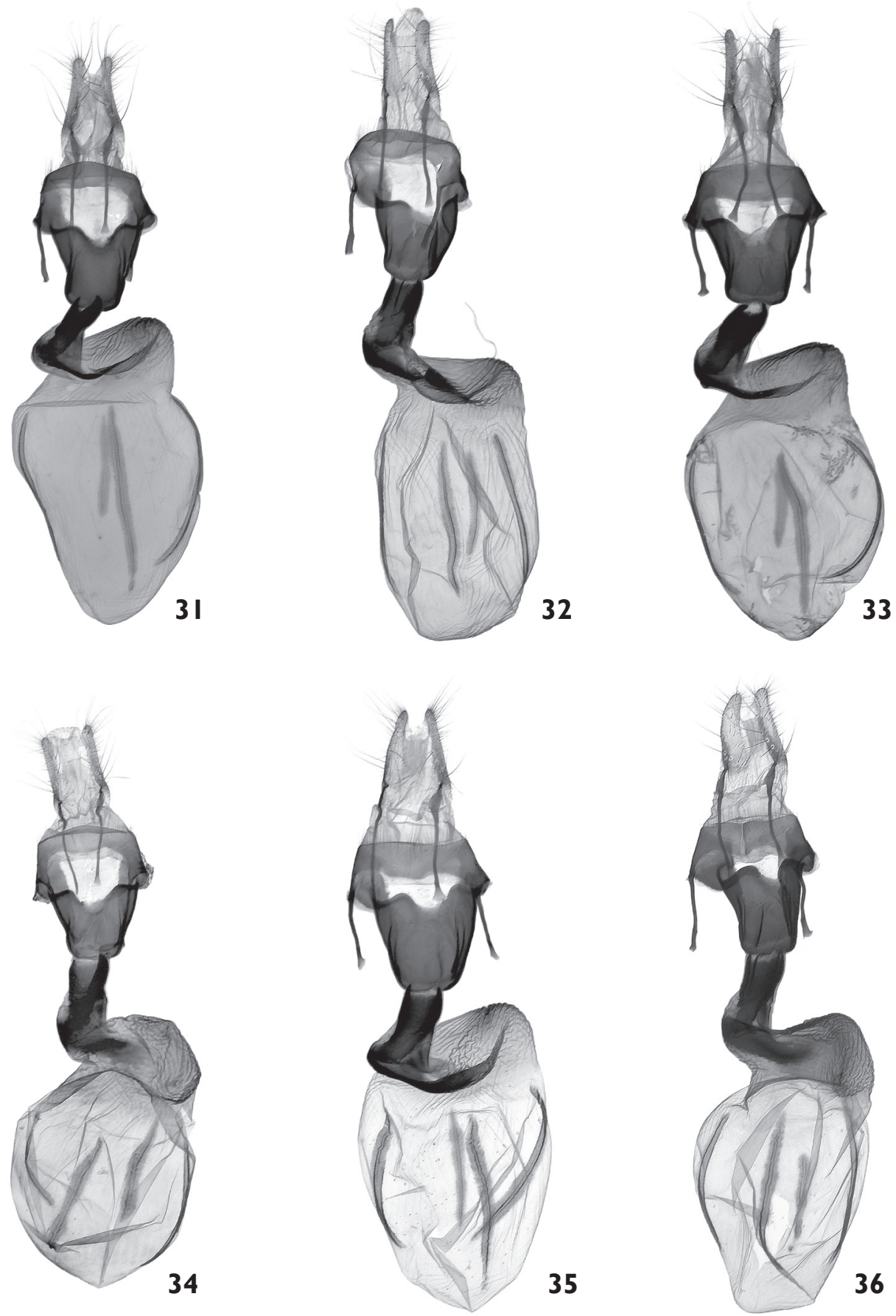

Figures $\mathbf{3}$ I-36. Female genitalia. 3 I-36 Polymixis serpentina serpentina $\mathbf{3}$ I NE Greece, Kirki, slide No. OP1339f 32 Central Greece, Amfissa, slide No. OP1015f 33 Greece, Peloponnes, slide No. OP1337f 34 Greece, Rhodos, slide No. OP1039f 35 Turkey, Antalya county, slide No. OP1036f 36 Turkey, Icel county, slide No. OP1028f. 

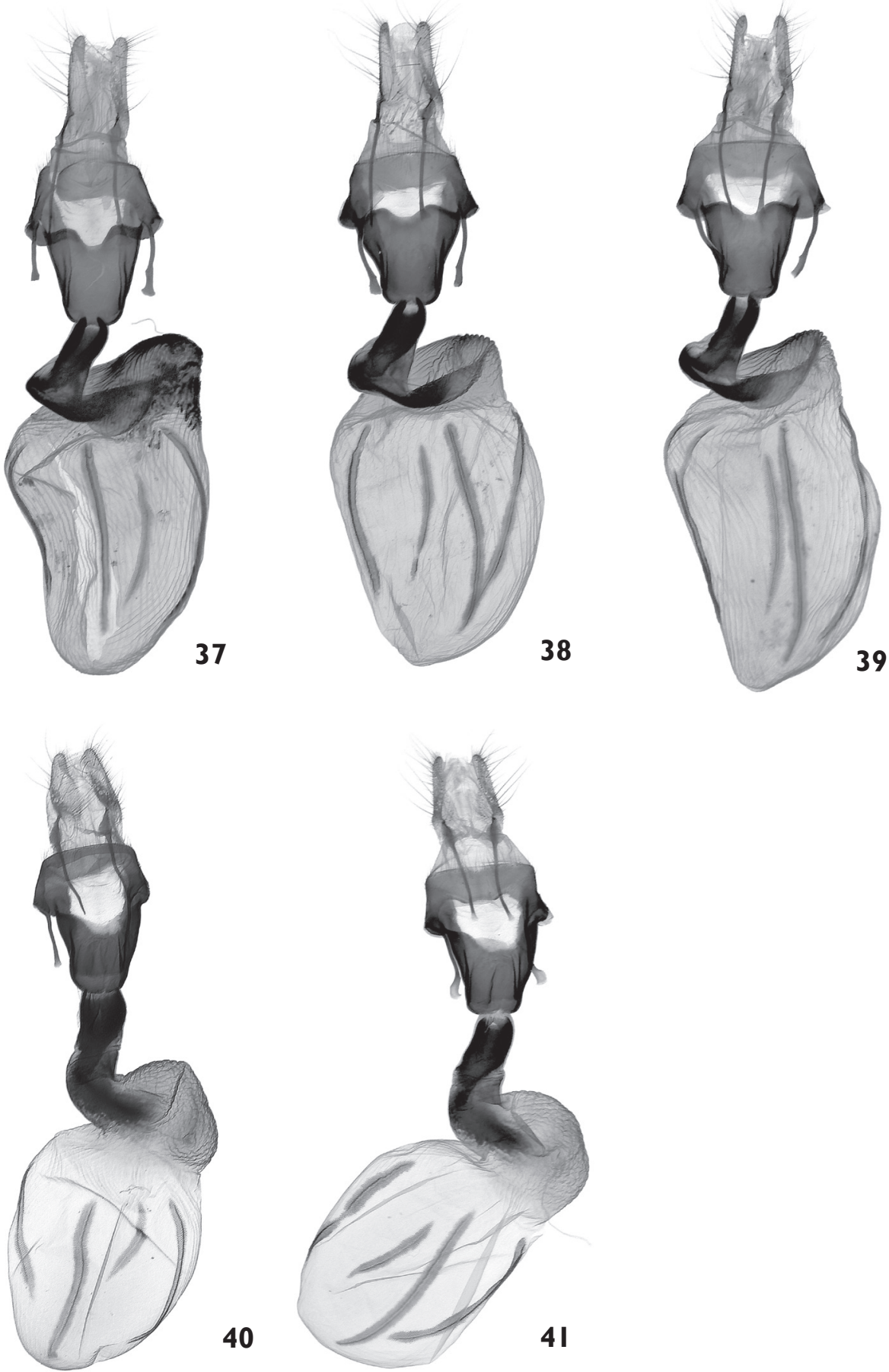

Figures 37-4I. Female genitalia. 37-39 P. serpentina minoica 37 Greece, Crete, slide No. OP1284f 38 Greece, Crete, slide No. OP1340f 39 Greece, Crete, slide No. OP1346f 40, 4 I P. iatnana 40 Cyprus, slide No. OP1031f 4 I Cyprus, slide No. OP1041f. 


\section{Polymixis iatnana Hacker, 1996, stat. n.}

http://species-id.net/wiki/Polymixis_iatnana

Figs 7,8

Material examined. Cyprus, Slide Nos; $\widehat{\partial}{ }^{\lambda}$ OP1030m Paratype, OP1282m, 우우 OP1031f, OP1041f.

Male genitalia (Figs 23, 24). The original description contains the following text about the genitalia structure: "Ohne Berücksichtigung der sowohl beim Männchen als auch beim Weibchen nahezu identischen Genitalstrukturen würde man sie für eine gut ausgeprägte Art betrachten“. The genitalia of both sexes show, however, clearly visible differences, especially in shape of juxta and antrum. $P$. iatnana has a wide, shield-like juxta with a wide posterior extension and very small drop-like lateral arms.

Female genitalia (Figs 40, 41). The female genitalia are characterized by the very wide and shallow concavity on the posterior margin of the antrum, which extends from one lateral edge to the other, whereas this incision is in the middle of the posterior margin in the two other subspecies.

\section{Acknowledgements}

I would like to express my sincere thanks to László Ronkay for his critical comments on the manuscript, to Marek Dvořák, Péter Gyulai and Gábor Ronkay for permission to use their collection material, and to Victor Gashtarov and Vasiliy Kravchenko, for help in finding material for research from Bulgaria and Israel. I am very grateful to Martin Lödl and Sabine Gaal (NHM Vienna) for access of the collection of the museum.

\section{References}

Beck H (1996) Systematische Liste der Noctuidae Europas (Lepidoptera, Noctuidae). Neue entomologische Nachrichten 36: 1-122.

Beck H (1999) Die Larven der Europäischen Noctuidae. Revision der Systematik der Noctuidae (Lepidoptera: Noctuidae). Herbipoliana 5(1): 1-859.

Fibiger M (1992) Contribution to the knowledge of the Lepidoptera fauna of Greece. Noctuidae in Crete during November 1991 - with a description of one new species and three new subspecies (Lepidoptera, Noctuidae). Esperiana 3: 379-390.

Hacker H (1996) Ergänzungen zu "Die Noctuidae Vorderasiens" und neuere Forschungsergebnisse zur Fauna der Türkei II (Lepidoptera). Esperiana 4: 273-330.

Ronkay L, Yela J, Hreblay M (2001) Hadeninae II. Noctuidae Europaeae, volume 5. Entomological Press, Sorø, 206 pp.

Witt Th J, Ronkay L (Eds) (2011) Lymantriinae - Arctiinae, including Phylogeny and Check List of the Quadrifid Noctuoidea of Europe. Noctuidae Europaeae, volume 13. Entomological Press, Sorø, 448 pp. 